\title{
Life on Chure and Siwalik Under the Extreme Threat of Lightning
}

\author{
Shriram Sharma ${ }^{1 *}$, Hari Bahadur KC ${ }^{2}$, Bishnu Neupane ${ }^{3}$, Suman Dhakal ${ }^{4}$ \\ ${ }^{1}$ Department of Physics, Amrit Campus, Tribhuvan University, Kathmandu, Nepal \\ Email:ramhome2@hotmail.com, sharmasr@amritcampus.edu.np, \\ ${ }^{2}$ Central Department of Physics, Kirtipur, Tribhuvan University, Kathmandu Nepal \\ Email:hkc@tucdp.edu.np \\ ${ }^{3}$ Department of Physics, Tri-Chandra Multiple Campus, Trihuvan University, Kathmandu Nepal email: bneupane98@, \\ gmail.com \\ ${ }^{4}$ Hariyoban Program, WWF Nepal, Baluwatar Kathmandu
}

(Received: 21 June, 2020, Received in revised form: 14 August, 2020, Accepted: 6 September, 2020, Available online)

\section{Highlights}

- Lightning is the second highest killer after earthquake in Nepal.

- Majority of the lightning fatalities have been reported from the Chure and Siwalik range in Nepal.

- The unsafe shelters, dependence of majority of the people on manual agriculture and lack of awareness in the Chure region can be attributed for large fatalities in the region.

- The height of the Chure/Siwalik range facing towards the southern plains could form a conducive environment for the occurrence of ground flashes and hence to number of fatalities.

\begin{abstract}
Of all the natural disasters in Nepal, lightning is the second highest killer after earthquake. According to the data available from the Disaster Risk Reduction (DRR) portal of Ministry of Home Affairs (MoFA), an average of 108 people are killed by lightning each year. As would be expected, fatalities over the high mountains are rare due to both low population and low lightning flash density. Surprisingly, most fatalities and injuries are reported over the hilly areas of the Siwalik and Chure range in the middle of Nepal, despite the southern region having both a significantly higher population and higher lightning flash density. The higher fatalities over the Chure and Siwalik can be attributed to their elevation leading to a smaller distance to the charge center in the cloud and meteorological conditions that may arise for the development of a turbulence in the lee waves at the interface of southern plains and middle hills.
\end{abstract}

Keywords: Disaster, Lightning Fatalities, Siwalik lightning, lightning injury,

\section{Introduction}

Lightning fatalities are ubiquitous around the globe. However, the exact data of fatalities and injuries are not available from most of the countries. Cooper and Holle (2019) has speculated that the global annual fatalities may be as high as 24,000 and that 240,000 people may get injured each year. This speculation was made based on the available demography of 26 countries and the lightning strike density. Holle (2016) reported that the fatality rates in developed countries is much lower than the same in the

${ }^{*}$ Corresponding author 
lesser developed countries. It was shown that the fatality rates with respect to the population is the highest in Malawi (84 people per million per year) whereas, it is lowest in the developed countries such as UK, Austria and Japan. Such discrepancy in the fatality rates have been attributed (Holle, 2016) to the following features in developing countries. 1) Fewer lightning-safe homes, workplaces, schools, and other facilities than in more developed countries. 2) High rate of labor-intensive manual agriculture. 3) Lack of awareness or data about lightning threat, its avoidance, and its medical treatments. 4) Fewer easily available fully enclosed metal-topped vehicles or similar enclosures.Exact numbers on fatalities and injuries from lightning are not available for most of countries. One estimate of global fatalities is several thousand (Gomes and AbKadir 2011), another is 6000 fatalities per year (Cardoso et al. 2011), and the third is 24000 fatalities per year (Holle and López 2003). Holle and Lopez also estimated 240,000 people injured each year based on lightning stroke density and populations in the tropical and subtropical areas of the world. Holle (2016) reported that the fatality rates in developed countries are much lower than in lesser-developed countries. Fatality rates were highest in Malawi (84 people per million per year) and lowest in developed countries such as the UK, Austria and Japan. Differences in fatality rates have been attributed to several factors in developing countries:

1) Fewer lightning-safe homes, workplaces, schools, and other facilities than in more developed countries.

2) High rate of labor-intensive manual agriculture.

3) Lack of awareness or data about the lightning threat, how to avoid injury, and medical treatment.

4) Fewer easily available fully enclosed metal-topped vehicles or similar enclosures.

Gomes and Kadir (2011) developed an empirical formula to estimate the annual death rate in a given region. The equation takes many factors into account such as lightning ground flash density, population density, literacy, fraction of urban population, etc. However, when this formula was applied to Mongolia, it was unsuccessful in estimating the death rate. Doljinsuren and Gomes (2015) suggested that other parameters including landscape topography may have a significant influence on annual deaths due to lightning.

Although lightning is a threat to people and livestock, particularly in the developing world, this natural hazard has largely been ignored in these countries. Lightning injury data are unavailable in the literature for most developing countries. In Nepal, too, lightning hazards are largely underrated, despite the fact that it is one of most potential natural hazards that people encounter. In the present study, we analyze the lightning fatalities and injuries in Nepal, and identify the lightning prone districts and the region. We have also attempted to interpret the possible reasons behind the vulnerability due to lightning hazards.

\section{Materials and Methods}

\section{Geography and weather patterns of Nepal}

Nepal is a country of diversified geographical configuration with altitudes as low as $59 \mathrm{~m}$ to as high as $8848 \mathrm{~m}$ above mean sea level (Fig 1). Over $83 \%$ of Nepal is hilly or mountainous, including the world's highest peak, Mt. Everest, and eight other peaks over $8000 \mathrm{~m}$. The Himalayan peaks cover the northern part of Nepal, the southern part is a plain, whereas much of the middle part is covered by hills. This geographic structure plays a vital role in the observed meteorological effects.

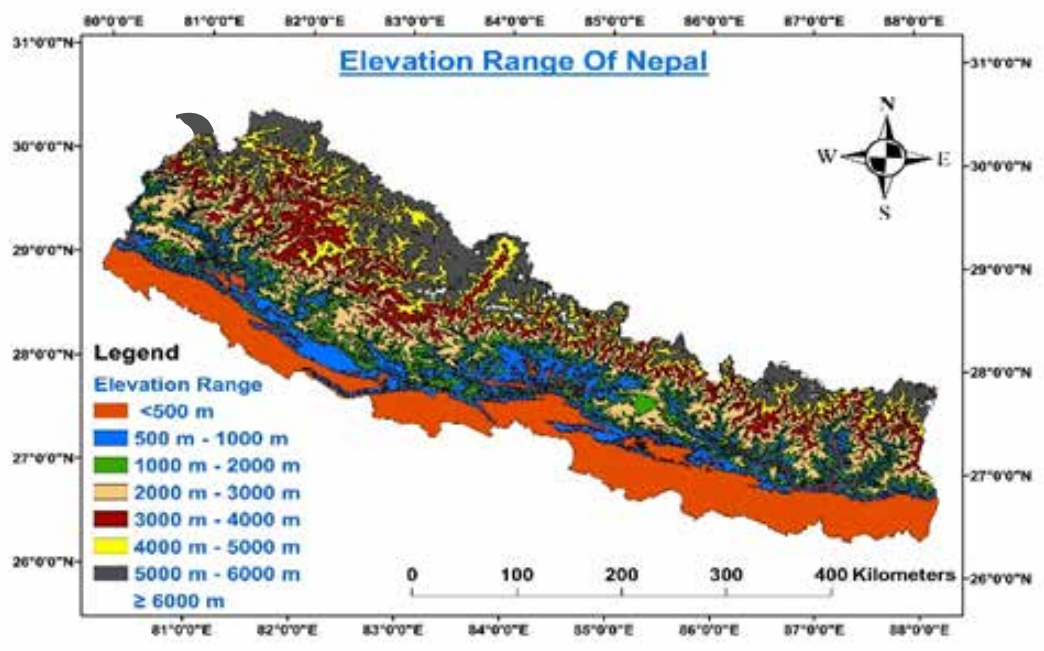

Fig 1: Topographic map of Nepal with elevation. 
Nepal is topographically divided into three regions: The Himalayas and its foothills make up the northern border of the country and covers $16 \%$ of the total land area. This northern region is very thinly populated with the inhabitants of less than $8 \%$ of the total population of Nepal. Most of the human dwellings are below $400 \mathrm{~m}$ altitude from the average sea level. The middle hills of the Mahabharat range and the Chure range, also called lesser Himalayas, cover about $65 \%$ of the total land area and are home to about $44 \%$ of the total population. The southern part of Nepal which also termed as Terai, is an extension of the Gangetic plains. The southern plain region covers about $17 \%$ of the total land area and is densely populated with about $48 \%$ of the total population and has highest population density among all the regions.

Monsoons occur during July and August, with heavy rainfalls resulting in landslides, floods and inundations. Thunderstorms and lightning occur mostly during the pre- and post-monsoon periods. The meteorological changes occurring in the Himalayan range have a role in the nature of lightning flashes. Thunderstorms generally begin in March (in the pre-monsoon) and cease by August (post-monsoon). The pre-monsoon period is the most active lightning period followed by the post-monsoon period, although monsoonal thunderstorms are also prevalent. Winter lightning is very rare, although lightning casualties and incidents have been reported.

Lightning occurs almost everywhere over Nepal; although it is relatively rare over the high mountains. In contrast, the southeast part of the country receives the highest number of lightning strokes followed by the Chure range (Fig. 2 and Fig 3). This is the range of hills that extends from Indus river of Pakistan in the west to the Brahmaputra river of India in the east. These Chure hills, also known as Siwalik hills, are the southernmost foothills of Himalayas, shaped like a hedge with an average elevation of $600 \mathrm{~m}$ to $1220 \mathrm{~m}$ above sea level.

The atmospheric structure and hydro-meteorological processes along the south slopes of the Himalayas are not well known or well documented, mainly because of the rugged and remote terrain.

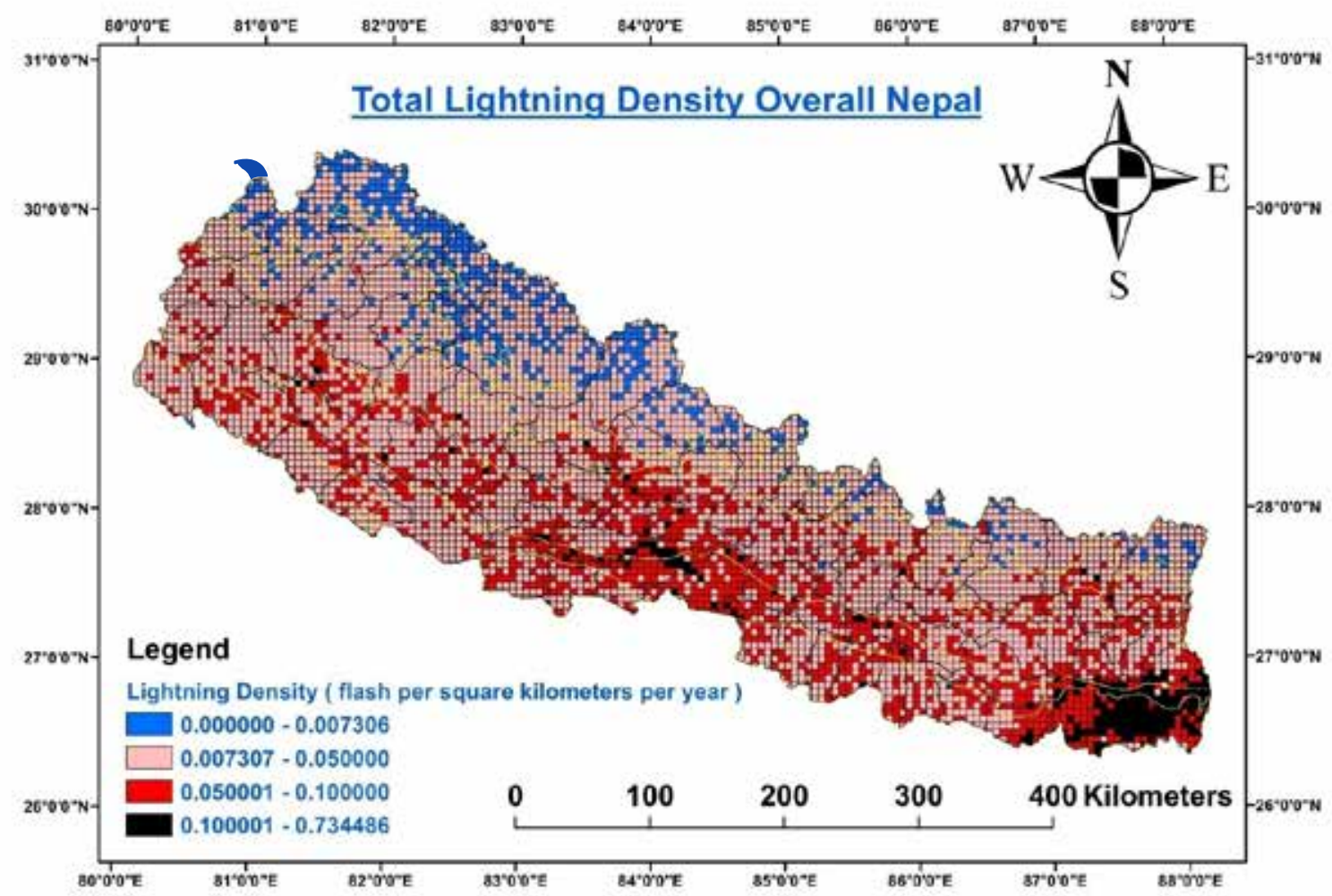

Fig 2: Lightning density map over Nepal with $5 \mathrm{~km} \times 5 \mathrm{~km}$ resolution using data obtained from WSI's Global Lightning Network and TOA technology.

Note: The stroke data presented in this study were obtained from 2011 to 2019 and hence recent map of Nepal could not be presented in this study. 
Also, the mountain range lies within several poor developing countries, such as Nepal, that do not have the resources to carry out sophisticated meteorological studies (Barros and Lang, (2002). Lightning stroke density is over 18 strokes km $\mathrm{km}^{-2}$ along the southern Nepal border, typically 4 to 8 strokes $\mathrm{km}^{-2} \mathrm{y}^{-1}$ in the central region, and very small densities are over the northern border. Recall that these densities are estimated to be $70 \%$ of the actual cloud-to-ground flash values.

In this study, we analyze the distribution of lightning activities over Nepal and compare the association of lightning fatalities with the altitude and population density.

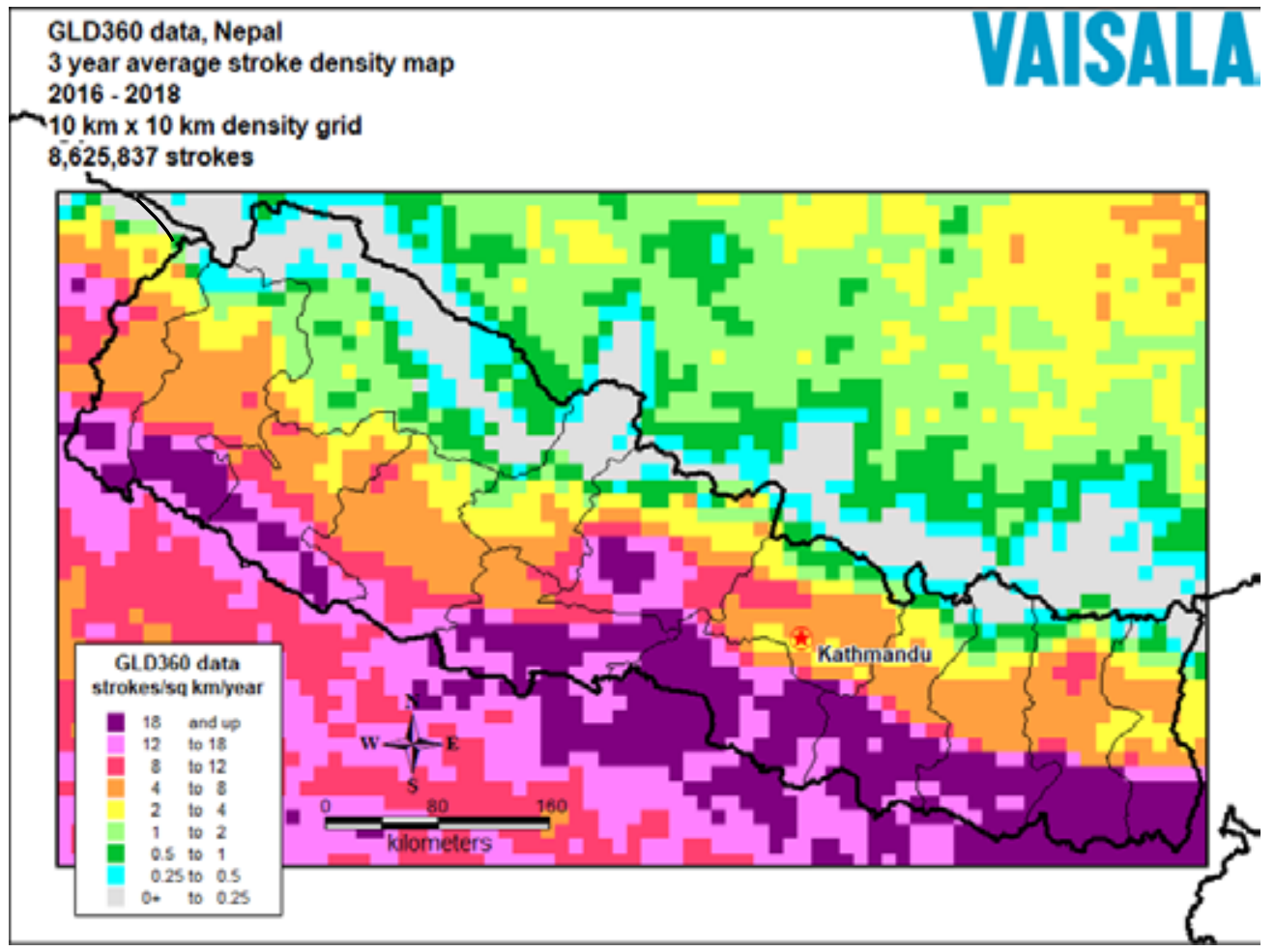

Fig 3: Average annual lightning stroke density over Nepal and adjacent regions with $10 \times 10 \mathrm{~km}$ resolution from Vaisala's Global Lightning Dataset GLD360 network from 2016-2018. A total of 8,625,837 strokes were detected in the three years (courtesy: Ronald Holle, VaisalaCorporaton).

\section{Methodology}

Lightning strikes were obtained being sensed and recorded by the sensors and Time of Arrival (TOA) detection system installed by Weather Services Institute's (WSI) Global Lightning Network. One of the sensors being installed at Nepal Academy of Science and Technology (NAST), Khumltar, Lalitpur. The data so obtained have been archived since 2010 and have been plotted in this study over Nepal using ARC-GIS software. In order to check the validity of the data obtained from WSI's sensor, lightning density map from Vaisala corporation was requested with a resolution of $10 \mathrm{X} 10 \mathrm{~km}^{2}$. Similarly, the demography of human fatalities and injuries were obtained from Disaster Risk Reduction (DRR) portal of ministry of home affairs of the Government of Nepal. The data so obtained from April 2011 to April 2020 were plotted over Nepal using ARC- GIS software. Analysis has been done using the lightning density map of Nepal and lightning fatalities and injuries map of Nepal.

\section{Results}

\section{Lightning data and fatality information}

Considering all the natural disaster that are common in Nepal, lightning has been the biggest killer after earthquake. Figure 4 depicts a comparison of the human casualty due to various hazards excluding earth quake. As is seen from the figure 4, 929 
people were killed since April 2011 till April 2020, followed by landslide that claimed 901 people during the same period.

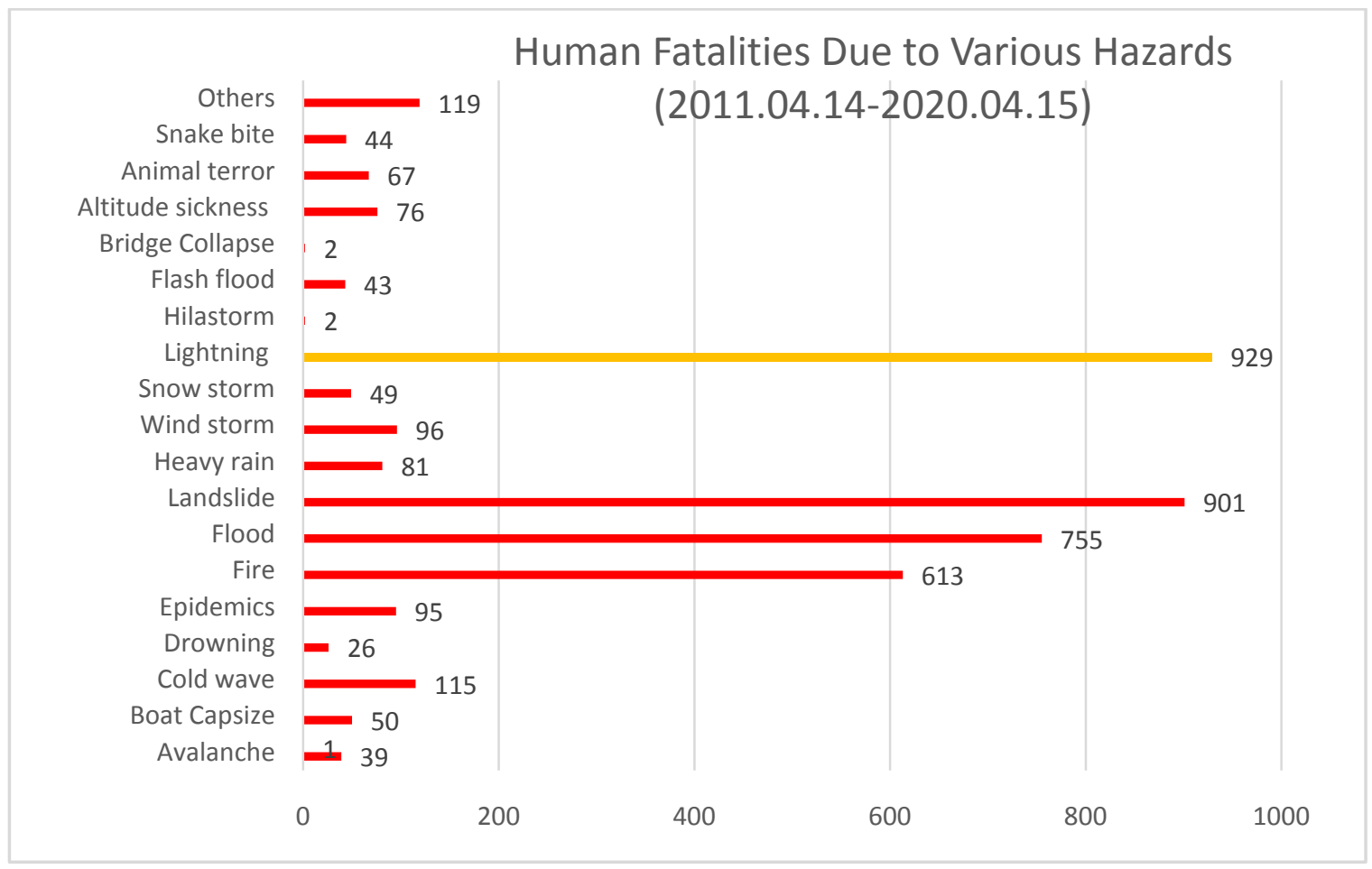

Fig 4: A comparative graph of human fatalities due to various natural hazards (except for earth quake) in Nepal during past 9 years (data source DRR Portal Ministry of Home Affairs Nepal). Lightning proves to be highest killer of all the disasters for the period of study.

\section{Lightning Fatalities and Injuries in Nepal (14April 2011- 13April 2020)}

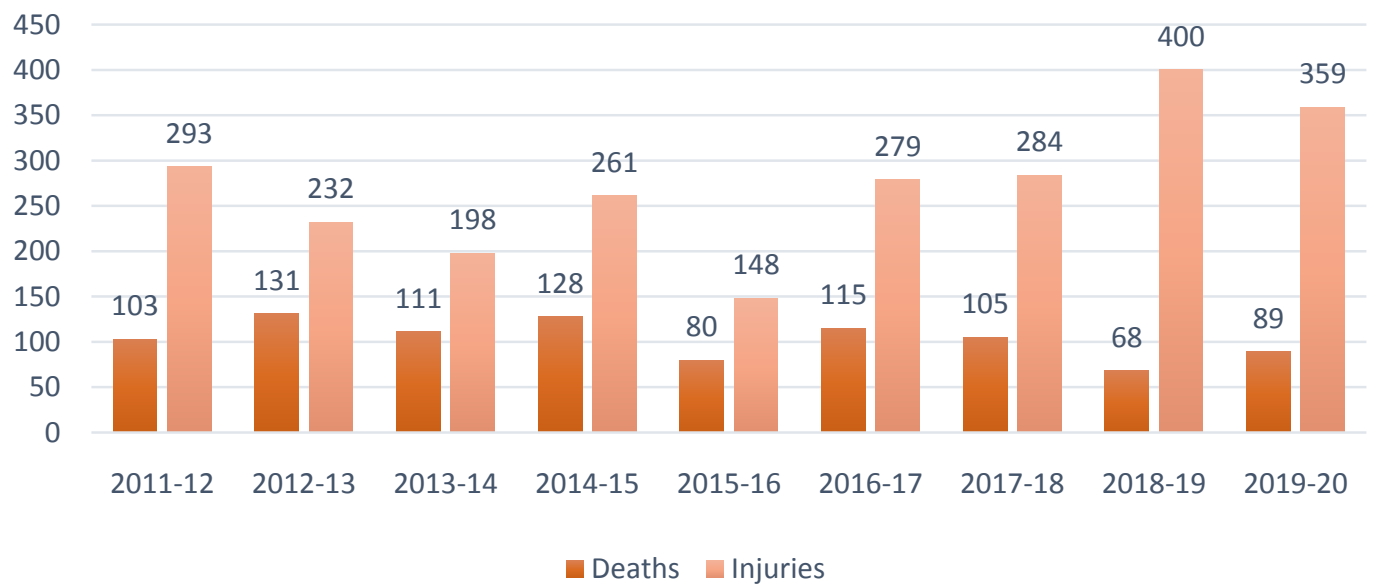

Fig 5:Annual lightning fatalities and injuries in Nepal from April 15, 2011 through April 14, 2020.

\section{Lightning occurrence over Nepal}

Lightning activity over Nepal has been continuously monitored in recent years by the Global Lightning Dataset GLD360 network that is owned and operated by Vaisala, Inc (Said et al. 2010) and WSI's Global Lightning Network (GLN) using TOA technique. Figure 2 and 3 show the spatial distribution of nearly 3 million strokes per year as detected for Nepal and adjacent regions. Figure 2 is the lightning map obtained from WSI's TOA system and Figure 3 is a lightning map obtained from Vaisala's GLD 360. The location accuracy of GLD360 over this region during the three years of the map in fig 3 is about $3 \mathrm{~km}$. The detection efficiency of cloud-to-ground flashes is about $70 \%$ in this region and time period. 
Fig 3 shows that the southern border of all of Nepal receives more lightning than elsewhere in the region. In particular, the southeastern plains region of Nepal receives maximum lightning strikes followed by the southern part of central region over the Siwalik or Chure range. The high mountains, stretching along the northern border with China from east to west, have considerably fewer lightning strikes.

The maximum at the base of the high mountains is attributable to the major elevation change that faces the influx of low-level moisture form the south during the pre-monsoon and monsoon seasons. This maximum has been observed to occur over all of the Indian Subcontinent (Nag et al. 2017). To the north of the band of maximum lightning,the frequency reduces quickly as the lowlevel moisture impinging on the mountain slopes is depleted. At the highest elevations, almost no thunderstorms exist because no low-level atmospheric water content is present. All three of these features, maximum on the low-altitude slopes, decrease in the valley behind the mountain barrier, and lack of lightning at highest elevations are evident in other locations around the world. The features are apparent in Colombia (Navarrete-Aldana et al. 2014), and in Venezuela, East Africa, the Andes, and Southeast Asia (Holle and Murphy 2017).

\section{Fatalities from lightning}

Lightning has become recognized as one of the major natural hazards in Nepal, claiming over 100 lives each year. Data obtained from the Disaster Risk Reduction (DRR) portal of Ministry of Home Affairs (MoHA), Nepal, show an average 108 people killed by lightning each year and 262 people injured (Fig. 5). As for many countries, it can be assumed that the data obtained from the DRR portal underestimates the true number as has been observed in many countries including U.S. (López et al. 1993).

The highest number of casualties (131) was recorded in the year 2012/13 and the least number (68) in 2018/19. During the last nine years, 929 people were killed, and 2454 people injured by lightning for a fatality rate of $3.7 /$ million per year. This number is higher than many other countries (Holle 2016).

\section{Population density}

Figure 6 shows the population density over the 77 districts of Nepal according to the 2011 census. As is seen, the southern plain districts are densely populated, followed by the hilly districts, whereas the mountainous region is sparsely populated.

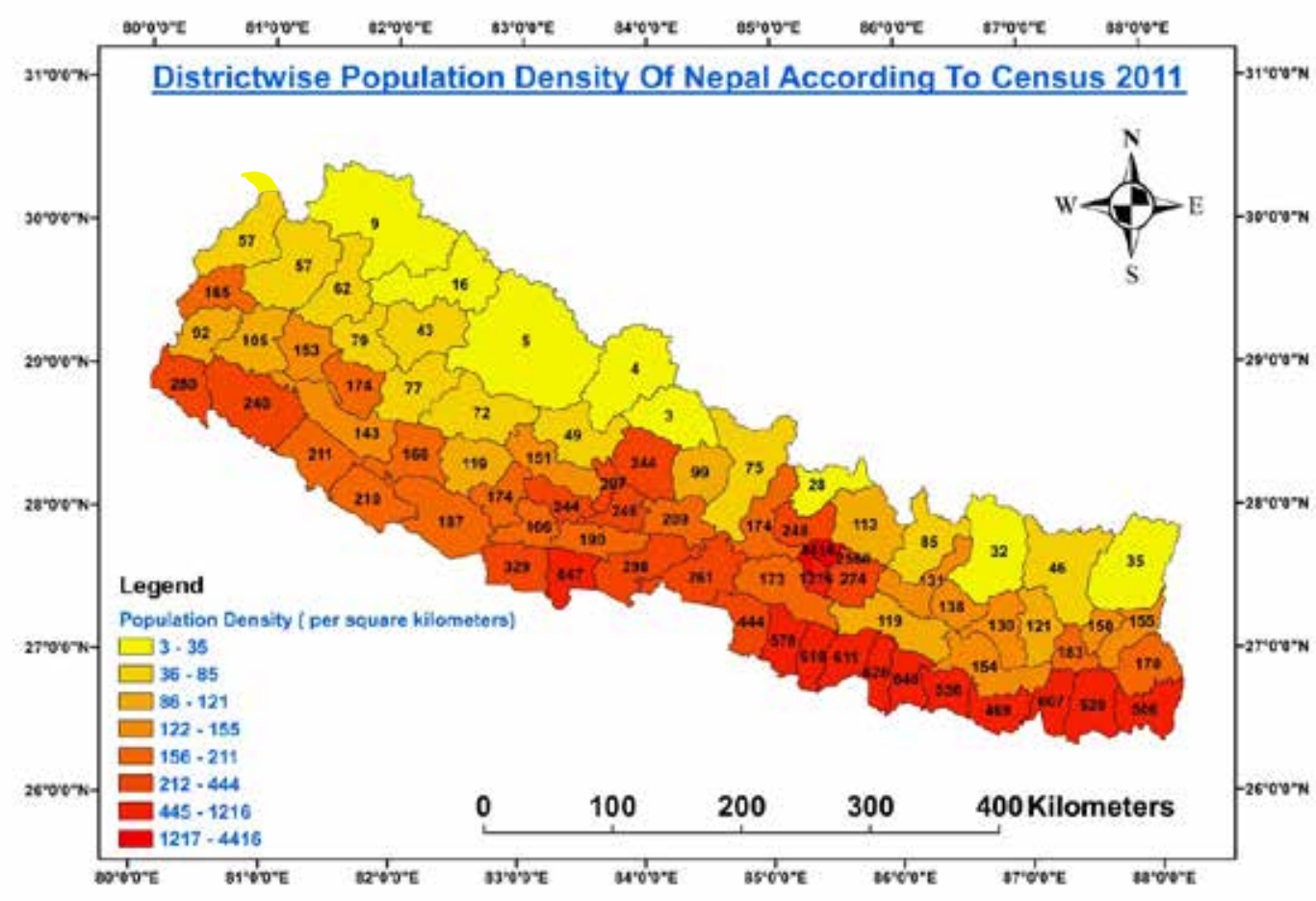

Fig 6: Population density of Nepal over all the districts using 2011 census data. 


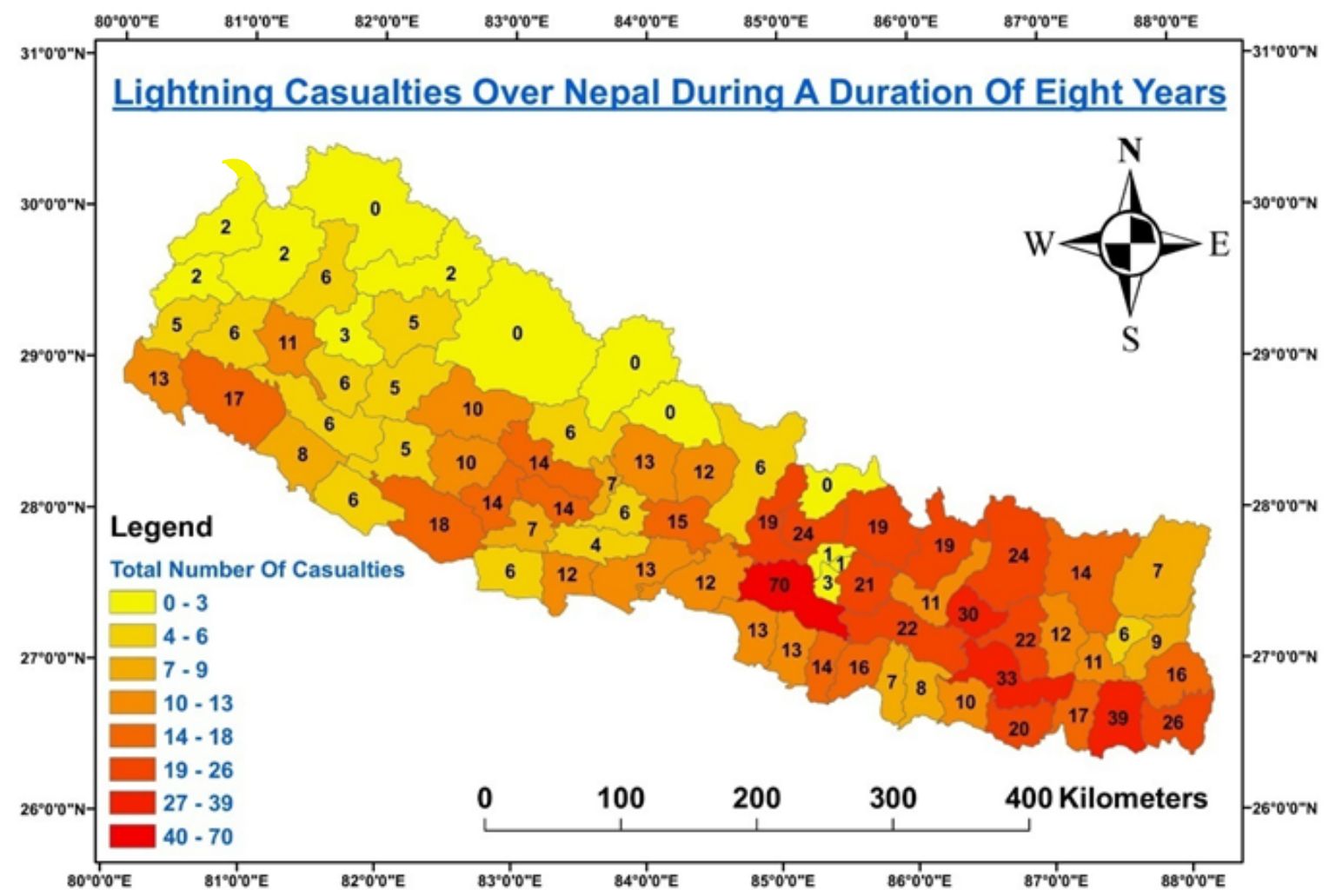

Fig 7: Spatial distribution of lightning fatalities over the 77 districts of Nepal.

Note: The demography for fatalities and injuries archived in the DRR portal of ministry of home affairs has not included the data from Limpiyadhura,lipulekh etc. that are currently included in the Nepal's updated map and hence this study did not include that area into consideration.

Figure 7 shows the spatial distribution of lightning fatalities in Nepal. Out of 929 fatalities, 577 were reported from the hilly region, 307 fatalities from the Terai plains region, and 45 fatalities from the mountainous districts. Of these 45 fatalities, none were reported from the high mountains above $6000 \mathrm{~m}$. Clearly, most of the fatalities are reported from the lesser Himalayas and Siwalik hills region.

Using only the number for the hilly (lesser Himalayas and Siwalik) region and Plain (Terai) region only, the fatality rate over the hilly.

\section{Discussion}

The majority of Nepal's land is cladded with high hills and mountains. The mountainous region has both sparse population and minimal lighting occurrence that can be attributed to less fatalities there. Furthermore, the negative charge center in the cloud over Nepal's latitude (i.e. $26-30^{\circ} \mathrm{N}$ ) is estimated at around $5000 \mathrm{~m}$ to $6000 \mathrm{~m}$ above the mean sea level and many of the mountain peaks are elevated over that height. This may lead to less occurrence of lightning strikes over the mountainous region.

Despite the densely populated region, the fatalities density in the plain region is comparatively less than that in the hilly region. The possible reason could be attributed to the occurrence of lesser amount of lightning ground flash as compared to the hilly region. Another possible contributing factor to the lesser number of fatalities in the plain region could be the number of steel reinforced houses that are considered to be safe shelter.

The type of shelter where the people in the hilly region live are likely a reason for the higher number of fatalities. Most people there live in houses with thatched roof of hay and other similar material. Such houses provide no protection against lightning. Further, the people living on the hills make their livelihood from labor intensive agriculture and outdoor activities, so they spend most of their time in the open. 
It is to be noted that there are some urban and suburban areas in the hilly region. The fatalities over such urbanized areas are negligible. The houses in the urban areas consist of reinforced steel or iron. This clearly indicates that the type of shelter and nature of human activities is the main reason for the higher fatalities on the hilly region.

In the future climate with increased average surface temperature, extreme weather events are expected and hence the possibility of severe lightning activities globally. Furthermore, one of the crucial factors that plays role in developing the thunderstorms is the percentage of aerosol in the atmosphere. It is very likely that the percentage of aerosol to increase primarily due to rapid industrialization of the neighboring countries as India and Bangladesh(Lin et al 2018).

Clearly, there is an acute need of installing lightning protection system on each house, particularly, in the hilly region. Also awareness raising programs should be conducted extensively in the hilly region.

\section{Limitation and future prospects}

The study on lightning activities in Nepal are in the rudimentary stage despite the fact that it is a potential threat to human life, livestock and physical property. This is the first time that we have mapped the lightning incidents and occurrence over Nepal. The occurrence of lightning has to be further varied with the aid of locally installed lightning network which could not be achieved in this study. Further, the potential threat has to be assessed in more detail by carefully studying the nature of hazards, status of the incident, time of incident, location and position of the victim etc. which could not be incorporated in the present study. Although, Department of Hydrology and Meteorology has already installed the lightning detection station over Nepal, they are yet to function properly and intermittently. The study of lightning activities has a great significance not only assessing the disaster but also to understand the climatic variation. This can be achieved only after monitoring the lightning activities continuously along with other meteorological variables.

\section{Conclusions}

The topographical diversity of Nepal not only bestows the natural beauty of its landscape but also incurs several natural disasters. Of all the disasters that Nepal experiences, earthquake is a major threat followed by the lightning hazards. The middle mountains and lesser Himalayas are most vulnerable regions to majority of these disasters, be it earthquake, lightning, landslides or erosion. Although, earthquake and landslides are considered to be major threat to these regions, lightning is largely underrated. In this context authors firmly believe that the outcome of this research work will be of paramount importance for 1) the disaster management Authority to take appropriate protective measures against lightning hazards and raise awareness accordingly, 2) Ministry of physical infrastructure development to identify suitable places for human settlement 3) Communication and Transmission companies to take appropriate protective measures on their system and 4) Universities and research institutes to conduct extensive research activities particularly in the prone regions.

\section{Acknowledgments}

This research work was partly supported by WWF's HariyobanProgramme. International Science Programme (ISP), of Uppsala University is acknowledged for the support at the instruments. Ryan Said at Vaisala is thanked for performance estimates of the GLD360 network. Author would also like to acknowledge WSI for providing us the lightning data and installing the lightning sensor in Nepal.

\section{References}

Barros A. P. and Lang T. J., 2003. Monitoring the Monsoon in the Himalayas: Observations in Central Nepal, June 2001, Monthly Weather Review volume. 131(7):1408-1427.

Cooper M. A. and Holle R. L., 2019.Reducing Lightning Injuries Worldwid, Springer Natural Hazards.Springer International Publishing, pp 3-4

Doljinsuren M. and Gomes C., 2015. Lightning incidents in Mongolia, Geomatics, Natural Hazards and Risk. 6 (8): 686-701. 
Gomes C. and Kadir M. Z. A. Ab., 2011. A Theoretical Approach to Estimate the Annual Lightning Hazards on Human Beings. Atmospheric Research. 101: 719-725

Gomes C., Kadir M. Z. A. Ab, Cooper M. A., 2012. Lightning safety scheme for sheltering structures in low-income societies and problematic environments: 2012 International Conference on Lightning Protection (ICLP), Vienna, 2012, pp. 1-11,

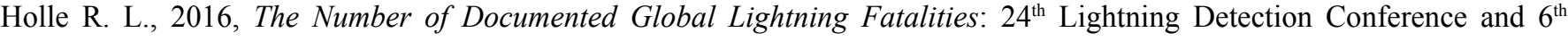
International Lightning Meteorology Conference, 18-21 April/San Diego, California USAG pp 1-4.

Holle, R.L., and M.J. Murphy, 2017: Lightning over three tropical lakes and the Strait of Malacca: Exploratory analyses.Monthly Weather Review.145: 4559-4573.

Holle, R.L., 2016: A summary of recent national-scale lightning fatality studies. Weather, Climate, and Society. 8: 35-42.

Lin, L., Xu, Y., Wang, Z., Diao, C., Dong, W., \&Xie, S.-P. 2018. Changes in extreme rainfall over India and China attributed to regional aerosol-cloud interaction during the late 20th century rapid industrialization. Geophysical Research Letters 45: $7857-7865$.

López, R.E., R.L. Holle, T. Heitkamp, M. Boyson, M. Cherington, and K. Langford, 1993: The underreporting of lightning injuries and deaths in Colorado. Bulletin of the American Meteorological Society. 74: 2171-2178.

Mäkelä A., Shrestha R., Karki R., 2014.Thunderstorm characteristics in Nepal during the pre-monsoon season 2012, Atmospheric Research. 137: 91-99.

Nag, A., R.L. Holle, and M. Murphy, 2017. Cloud-to-ground lightning over the Indian subcontinent: Postprints, $8^{\text {th }}$ Conference on the Meteorological Applications of Lightning Data, Seattle, Washington, American Meteorological Society, 6 pp.

Navarrete-Aldana, N., M.A. Cooper, and R.L. Holle, 2014: Lightning fatalities in Colombia from 2000 to 2009 , Natural Hazards. 74: $1349-1362$.

Said, R.K., Inan, U., and Cummins, K.L, 2010. Long-range lightning geolocation using a VLF radio atmospheric waveform bank, Journal of Geophysical Research. 115 (D23108): 1-19 